\title{
Article \\ Experimental and Analytical Study of Horizontally Curved I-Girders Subjected to Equal End Moments
}

\author{
Jeonghyeon Lim ${ }^{1}\left(\right.$, Young-Jong Kang ${ }^{1}{ }^{\oplus}$, Jeonghwa Lee ${ }^{2}\left(\right.$, Seungjun Kim $^{1}{ }^{1}$ and Keesei Lee ${ }^{3, *}$ \\ 1 School of Civil, Environmental and Architectural Engineering, Korea University, Seoul 02841, Korea; \\ bestcivileng@korea.ac.kr (J.L.); yjkang@korea.ac.kr (Y.-J.K.); rocksmell@korea.ac.kr (S.K.) \\ 2 Future and Fusion Laboratory of Architectural, Civil and Environmental Engineering (F-ACE Lab), \\ Korea University, Seoul 02841, Korea; qevno@korea.ac.kr \\ 3 Department of Urban Infrastructure Research, Seoul Institute of Technology, Seoul 03909, Korea \\ * Correspondence: kslee@sit.re.kr; Tel.: +82-2-6912-0934
}

Citation: Lim, J.; Kang, Y.-J.; Lee, J.; Kim, S.; Lee, K. Experimental and Analytical Study of Horizontally Curved I-Girders Subjected to Equal End Moments. Metals 2021, 11, 1132. https://doi.org/10.3390/met11071132

Academic Editor: Thomas Schenk

Received: 25 June 2021

Accepted: 16 July 2021

Published: 17 July 2021

Publisher's Note: MDPI stays neutral with regard to jurisdictional claims in published maps and institutional affiliations.

Copyright: (C) 2021 by the authors. Licensee MDPI, Basel, Switzerland. This article is an open access article distributed under the terms and conditions of the Creative Commons Attribution (CC BY) license (https:// creativecommons.org/licenses/by/ $4.0 /)$.

\begin{abstract}
If bending and torsional moments are applied to an I-shaped beam member, the coupling of those two forces could reduce the bending moment capacity of that member. Therefore, the interaction between bending and torsional moments is an important issue for horizontally curved members that are always simultaneously subjected to bending and torsion. In this study, the behavior of the horizontally curved steel I-beam was investigated through numerical analysis. The ultimate state of sharply curved members that showed large displacement was defined in accordance with the stiffness reduction ratio to consist of strength curves. Based on the analysis results, interaction curves were established, and a strength equation was derived. The uniform torsional moment capacity, curvature, and slenderness parameters were considered in the equation, which were the main factors that affected the ultimate strength of curved members. The curvature effect was considered individually, so that the strength of the straight or curved girder could be estimated with a unified equation. To verify the accuracy of the suggested equation, experimental studies were also conducted. Consequently, the suggested equation shows very good agreement with the test results, and is expected to provide useful information for the design of curved members.
\end{abstract}

Keywords: curved; torsion; interaction; nonlinear; experiment; strength

\section{Introduction}

As road networks are becoming more complex, the use of curved bridges is increasing for highway interchanges or overpasses, etc. Even though curved girders are meaningful in terms of both economic feasibility and aesthetic pleasure, they can experience a significant torsional moment due to their inherent geometric characteristics. Since the three-dimensional behavior of a curved member leads to highly nonlinear behavior, the coupling between bending and torsional moments should be considered in the design process to investigate the member strength.

If local stability is prevented, the ultimate moment strength of the straight steel Ishaped member should be governed by lateral torsional buckling (LTB), which could be expressed as a function of unbraced length. It is well-known that the initial imperfection of a straight girder affects the LTB strength of members. The initial curvature of a curved member could be regarded as a large degree of initial imperfection; therefore, it is obvious that the ultimate strength should be governed by the curvature. Hence, it is desirable that the straight girder should be considered as a special case among the members with countless cases of initial imperfection (or curvature). In other words, the general strength equation should take the curvature effect into account. 


\section{Background}

There have been many efforts to investigate the behavior of horizontally curved Igirders. In order to investigate the ultimate strength of a curved member, the transfer matrix method was used by Fukumoto et al. in 1981 [1]. Thereafter, the transfer matrix was applied to curved-beam-related research by several researchers [2-4]. However, the method was complicated, and the strength could not be accurately investigated. After the curved beam theory was established by Kang and Yoo [5,6], the behavior and strength of curved beams began to be highlighted. Pi and Trahair [7] tried to show the curvature effect using an analytical approach. There were no approximations for simplifying torsional behavior, but material nonlinearity was not included in their study. Thereafter, Pi et al. [8] investigated the fully nonlinear behavior of curved I-beams. By using a curved beam element, the coupling between bending and torsional moments was analyzed. Based on this research, Pi and Bradford [9] suggested a bending-torsional moment interaction equation for curved I-girders. Although the equation could consider bracing condition (continuously, centrally, and unbraced beams), it led to conservative results.

On the other hand, the ultimate strength equation was suggested by Yoo and Davidson [10] in 1997, and the same authors' follow-up study verified the equation [11]. According to their results, the strength of curved members could be evaluated by multiplying the critical moment ratio by the strength of straight girders. However, since the equation was derived based on linear elastic analysis results, strength could be overestimated for members that showed highly nonlinear behavior.

Curved-beam-related research continued until recently. Fasl et al. [12] performed a field test to measure stress and deflection for a horizontally curved steel I-girder bridge during construction. A comparison of field-monitored results to finite-element analysis was also introduced. Although their study provides invaluable insight regarding the behavior of the horizontally curved bridge during construction, the ultimate behavior was not discussed. Amani and Alinia [13] carried out a parametric study with multi-girder structural systems. They found that the ultimate strength of one girder in the superstructure could be predicted by modeling a single girder model. Issa-El-Khoury et al. [14] studied the flexure-shear interaction for the horizontally curved I-girder, in order to examine the effect of longitudinal stiffener on the web. Although their study was mainly focused on finding the optimal position of longitudinal stiffeners, it showed the importance of flexure-shear interaction for horizontally curved members. The latest research was conducted by Tsiptsis and Sapountazakis [15]. They adopted a boundary element method for beam formulation. This was available for curved beams with arbitrary sections, and provided highly accurate results. However, they discussed neither the behavior nor the strength of curved members.

There were also many efforts to demonstrate the behavior of curved bridges through experimental study. McElwain and Laman [16] gathered response data from real structure and compared those data with analysis results. The accuracy of grillage models was evaluated, and dynamic load allowance was highlighted. Shanmugam et al. [17] carried out tests to provide an understanding of tension field action in the curved web panels. Focusing on the construction sequence of horizontally curved bridges, Linzell et al. [18] performed an experimental study. However, these studies were not carried out for member strength. Thevendran et al. $[19,20]$ conducted analytical and experimental studies on the load-carrying capacity of composite curved girders and investigated the failure mode of a curved superstructure. Tan and Uy [21,22] derived a bending-torsion interaction equation of the straight and curved composite girder through experimental studies. However, the interaction curves were not unified enough to consider various radii of curvature.

The LTB of the straight girder can be defined by observing the out-of-plane and rotational displacement of the section. In contrast, the horizontally curved members should always resist torsional moment, even under gravitational loading. In other words, rotational displacement is inevitable behavior for curved girders. Lee et al. [23] defined this behavior as lateral torsional vertical behavior (LTV), and suggested an ultimate strength equation for the horizontally curved I-shaped members. In their study, the main factors 
that affect strength were investigated and reflected in a strength equation. However, the equation is applicable to girders that were shorter than the compact unbraced length, $L_{P}$.

In this research, an analytical study was performed in order to examine the ultimate behavior of horizontally curved I-girders that were simply supported and subjected to equal end moments. The strength equation was derived based on the analysis results, and the accuracy of the equation was verified by experimental study. The equations suggested by the authors resulted in good correlations and could cover the curved members, regardless of the unbraced length or curvature.

\section{Finite Element Analysis}

\subsection{Analysis Scheme}

Three-dimensional models were employed using ABAQUS 6.13(DASSAULT SYSTEMES Inc., Paris, France). The girders were modeled using a four-node shell element, S4R. Geometrical and material nonlinearities were considered, and the material was assumed to have $350 \mathrm{MPa}$ of yield stress with elastic perfect plastic behavior. Since the buckling behavior could show a falling load path, the displacement control method (Riks option in Abaqus) was used for the solution method. In this method, 0.00001 and 0.01 arc lengths were used for minimum and maximum arc length, respectively. In order to analyze the interaction of shear and normal stresses, Von Mises' yield criteria were adopted. The Galambos and Ketter residual stress pattern [24] was applied, and the self-equilibrium was checked before analysis.

The LTB strength of the straight girder was computed under pure moment conditions, which is the worst-case scenario. Equal end moments were applied by introducing a set of concentrated loads at each end, as shown in Figure 1. Since the point load at the free end might cause a local failure due to the stress concentration, the loading point should be reinforced. The three-dimensional beam element, B31, was used for a dummy element, attached at the loading point. However, dummy elements should be used carefully, since they can affect member behavior. In this study, the stiffness of the dummy beam was determined according to Lee et al. [23]. The dummy beam was selected to have a circular section, with a diameter that is $75 \%$ of the flange thickness. Figure 2 shows the boundary conditions for pin and roller support. Since there is no vertical component with equal end moment loading conditions, the number of vertical restraints could be minimized. Hence, the vertical restraint was applied at the centroid of each end, while the rotational displacement was restrained by introducing the horizontal restraints at the centroid, and the junctions between flanges and web. Note that all the nodes and boundary condition were defined with respect to the cylindrical coordinates represented in Figure 2.

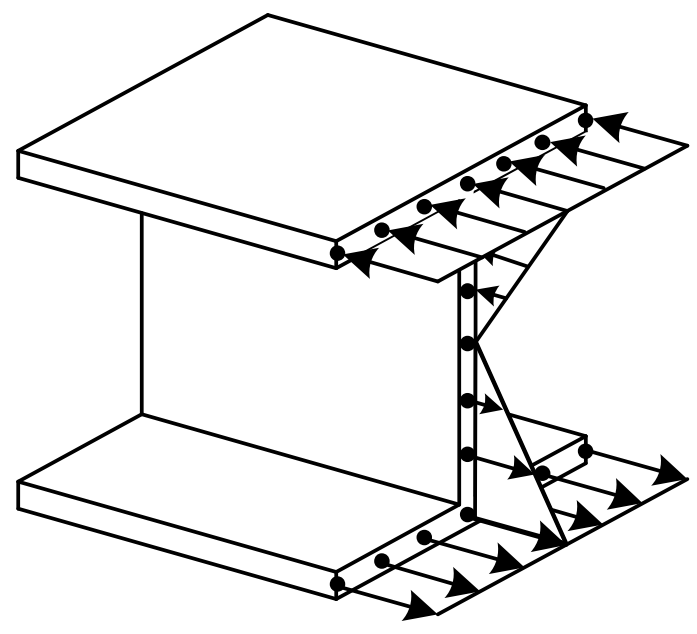

Figure 1. Loading Condition; End Moment. 


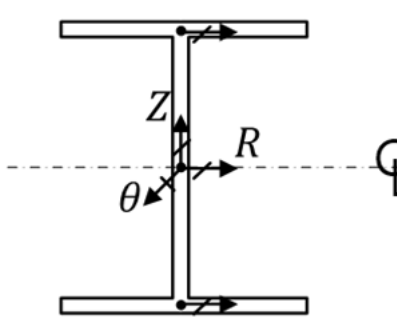

Hinge

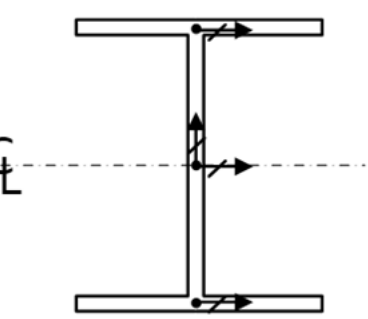

Roller

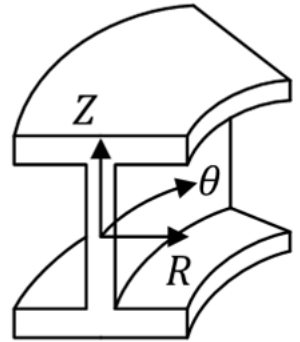

Coordinate System

Figure 2. Boundary Condition.

In order to investigate LTB behavior, initial imperfections should be applied to perfect straight members. As described in Section 1, initial imperfections do not have to be employed for the curved member, because the curvature could be regarded as an initial imperfection. However, initial imperfections were applied to all models so that they were analyzed under the same condition. Lee et al. [23] carried out parametric analysis to determine the amount of initial imperfection. According to their results, $500 / \mathrm{L}$ of horizontal displacement was applied at the center of beam before the analysis, with 1/500 radian of rotational displacement.

\subsection{Analysis Models}

Two arbitrary sections and one ready-made section were selected for finite-element analyses. The sections are all doubly symmetric I-shaped, and Table 1 shows the dimension of each section. Sec-A\#2 is provided in the AISC Steel Construction Manual (S24 × 121) [25].

Table 1. Dimension of Sections.

\begin{tabular}{cccc}
\hline (Unit: $\mathbf{m m}$ ) & Sec-A\#1 & Sec-A\#2 & Sec-A\#3 \\
\hline$h$ & 320 & 594.614 & 1000 \\
$b_{f}$ & 80 & 204.470 & 250 \\
$t_{f}$ & 15 & 27.686 & 35 \\
$t_{w}$ & 12 & 20.320 & 25 \\
\hline
\end{tabular}

$t_{f}$ : flange thickness $t_{w}$ : web thickness $h$ : depth of section $b_{f}:$ flange width.

A total of 342 beams were analyzed according to slenderness parameters and the subtended angle. The slenderness parameter, $\lambda$, was defined as Equation (1), where the linear elastic lateral torsional buckling moment, $M_{o c r}$, could be obtained using Equation (2) [26]. Since the linear elastic buckling strength contains the material and geometrical properties of the member, the ultimate moment strength of each model could effectively be normalized. In the analysis, $\lambda^{2}$ was considered between 0.2 and 2.0 , with intervals of 0.1 , and the subtended angle, $\theta$, varied from ( 0 (=straight girder) to 60$)^{\circ}$. Table 2 lists the parameters.

$$
\lambda=\sqrt{\frac{M_{P}}{M_{o c r}}}
$$

where $M_{P}$ is plastic moment capacity; $M_{o c r}$ is linear elastic lateral torsional buckling moment of the corresponding straight girder.

$$
M_{o c r}=\frac{\pi^{2} E I_{z}}{L^{2}} \sqrt{\frac{C_{w}}{I_{z}}+\frac{L^{2} G K}{\pi^{2} E I_{z}}}
$$

where $E$ is Young's modulus; $I_{z}$ is second moment of inertia with respect to the minor axis; $C_{w}$ is warping constant $\left(=I_{z} h^{2} / 4\right)$; $L$ is unbraced length; $G$ is shear modulus; $K$ is torsional constant. 
Table 2. Model Parameters.

\begin{tabular}{cc}
\hline Slenderness Parameter $(\lambda)$ & $0.2 \sim 2.0$ with interval of 0.1 \\
\hline Subtended Angle $(\theta)$ & $0^{\circ}, 5^{\circ}, 10^{\circ}, 30^{\circ}, 45^{\circ}, 60^{\circ}$ \\
\hline
\end{tabular}

\subsection{Analysis Results}

Figure 3 shows the load-displacement curves of straight girder models for Section 1 (note that the other sections show similar trends). The $Y$-axis of each graph shows the applied moment, generalized by division of the plastic moment, $M_{P}$. The displacements were selected at the shear center of mid-span. The ultimate moment was affected by the slenderness parameter, and the horizontal and rotational displacements were mostly observed after the maximum moment (peak point) occurred. In brief, the straight members showed typical bifurcation type buckling behaviors.
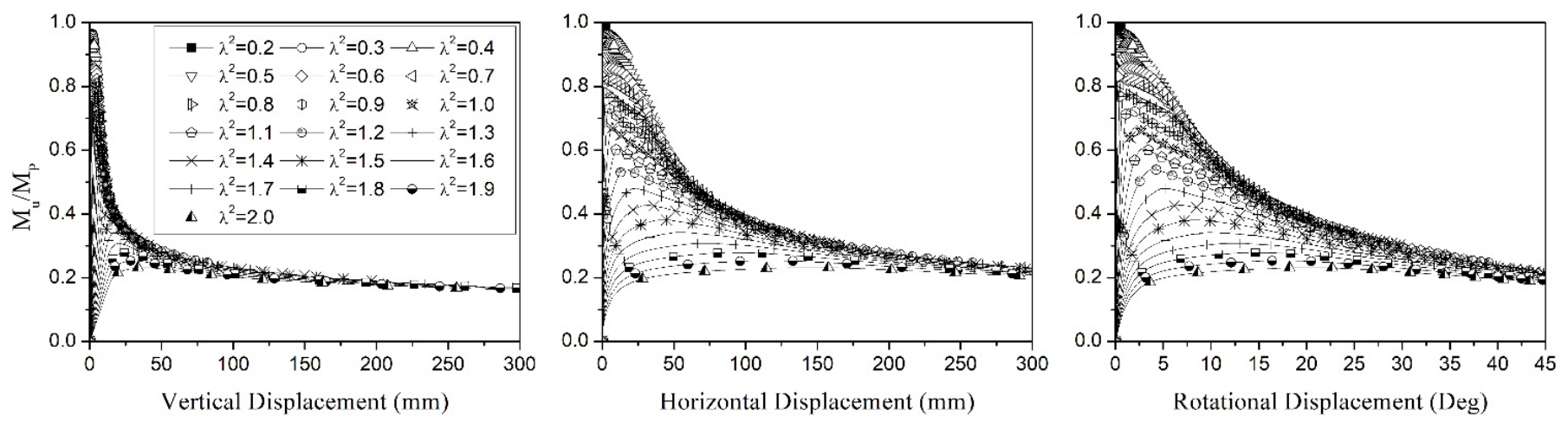

Figure 3. Load-Displacement Curve of Straight Girder-Sec\#1.

On the other hand, curved members showed significantly decreased ultimate moments compared to straight girders. For example, the ultimate moments of curved members that have a $60^{\circ}$ subtended angle were less than $30 \%$ compared to the corresponding straight girders (Figure 4). Unlike straight members, the rotational displacements were initiated shortly after the load was applied, as the torsional moment was generated by curved geometry. This was far from being a bifurcation buckling behavior; therefore, the strength of curved members should be estimated by taking advantage of the bending and torsional moment interaction. The horizontal displacement pattern is also noteworthy. As the member rotates with respect to the centerline between two supports, the final (maximum) horizontal displacement of each member is smaller than those of the corresponding straight girder.
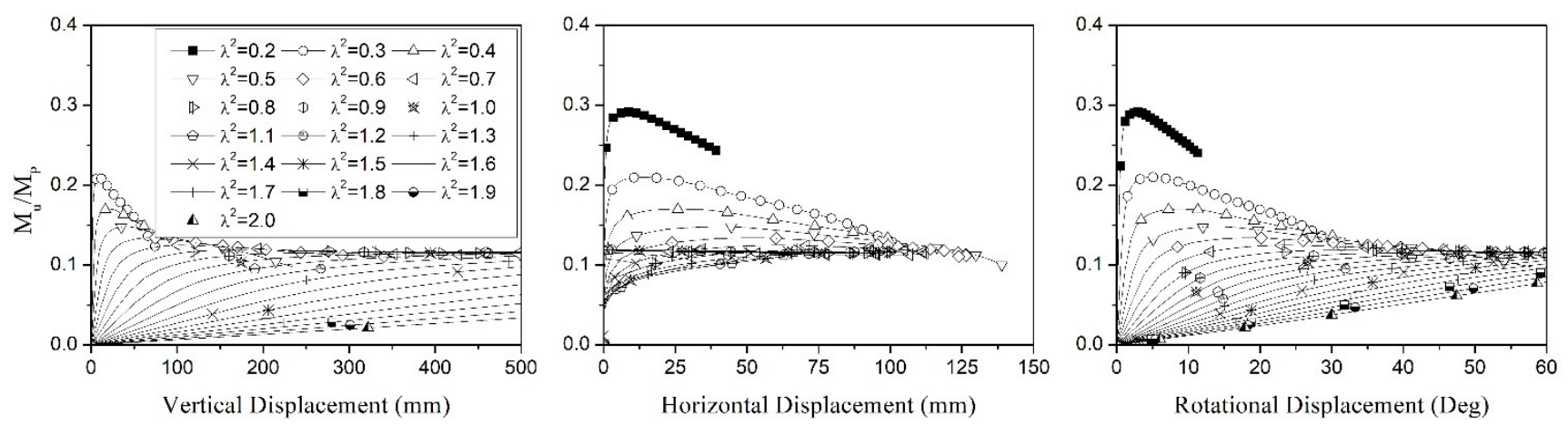

Figure 4. Load-Displacement Curve of Curved Girder $\left(\theta=60^{\circ}\right)$-Sec\#1.

Moreover, in the case of slender curved members, the maximum moment could not be defined by taking the peak point of load-displacement curves, since the stiffness (slope of $\mathrm{M}_{\mathrm{u}} / \mathrm{M}_{\mathrm{P}}$-Displacement curve) was too small, or there was no definite peak point. Therefore, 
in this study, the ultimate moment strength was determined when the member lost about $90 \%$ of its major bending stiffness compared to the initial stiffness. In other words, the stiffness was calculated for every load step, and the ultimate moment was defined when the current-to-initial stiffness ratio was less than 0.1 (note that the initial stiffness was obtained by taking the average of the first five steps).

Figure 5 compares the maximum moments, defined by taking the peak point, and using the stiffness ratio. Since the straight models had a definite peak point at the loaddisplacement curve, the accuracy could be verified by comparing the ultimate moments obtained by the two different methods. The ultimate strength could be obtained with an average difference of less than $1 \%(0.689 \%)$. Figure $5 \mathrm{~b}$ shows that the method provided very good results, even for the sharply curved members.

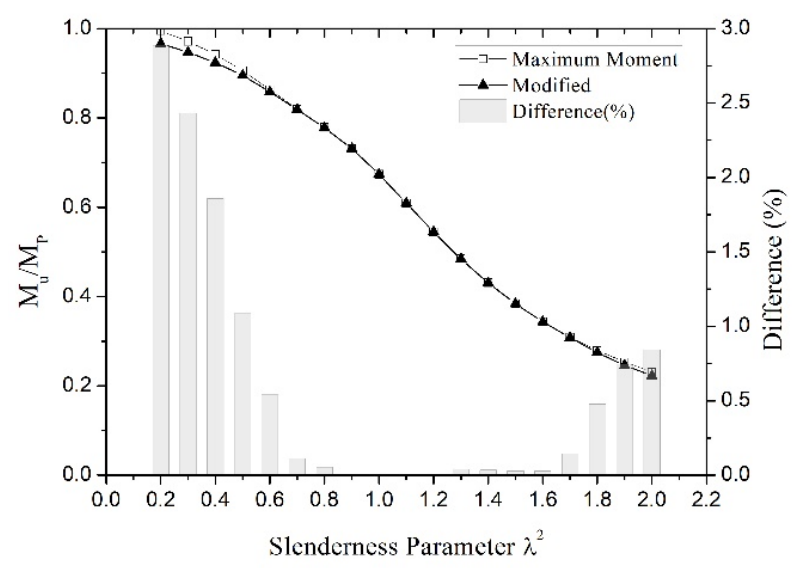

(a)

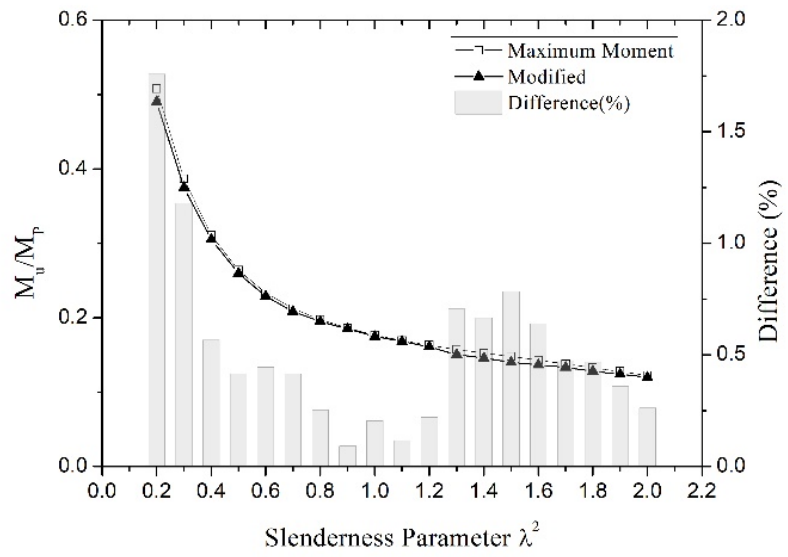

(b)

Figure 5. Ultimate Moments Obtained by Two Different Methods: (a) straight members; (b) curved members.

Finally, Figure 6 shows the strength curves that could be obtained for all models according to the slenderness parameter and subtended angle. Straight models showed typical LTB strength curves that approached the Euler hyperbola near the point $\lambda=1.4\left(\lambda^{2}=2.0\right)$, which indicates slender members. Note that the three different sections showed almost identical trends, both qualitatively and quantitatively. The ultimate moment strength was significantly reduced as the subtended angle increased, but the strength and curvature did not show a linear relationship. Another important consideration is that curved members could not resist the plastic moment, even though the slenderness parameters were small enough. Therefore, the interaction between bending and torsion should be considered for all curved members, regardless of slenderness.
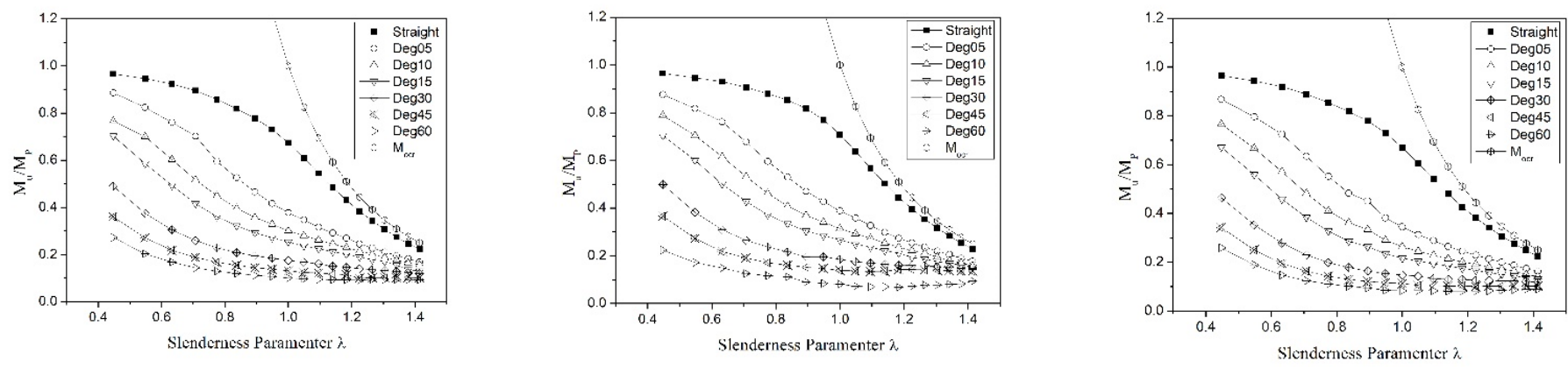

Figure 6. Ultimate Moment Strength Curve.

It is also noteworthy that the strength of the curved member showed convex downward curves, while the straight girders showed convex upward curves. In other words, as the slenderness increased, the strength of the curved members drastically decreased. 


\subsection{Ultimate Strength Equation}

The lateral torsional buckling behavior was divided into three parts per unbraced length in the current design specification. AASHTO LRFD Design Specifications [27] (hereafter referred to as "AASHTO") suggests compact and non-compact unbraced lengths, in order to define inelastic and elastic buckling behavior. According to AASHTO, plastic moment strength governs the ultimate behavior when the unbraced length, $L_{b}$, is shorter than the compact unbraced length, $L_{P}$. If the $L_{b}$ is greater than the compact unbraced length $\left(L_{P}\right)$ and smaller than the non-compact unbraced length $\left(L_{r}\right)$, inelastic buckling should govern the behavior. Lastly, linear buckling could be a dominant failure mode for a girder with an unbraced length longer than $L_{r}$. However, as mentioned in the previous section, the curved member cannot resist plastic moment, regardless of the unbraced length or slenderness parameter. This means that there are only inelastic and elastic buckling ranges for curved members. In this section, the inelastic buckling strength equation for the horizontally curved I-girder was derived based on the analysis results.

Figure 7 shows the failure modes of straight and curved girders with a 0.63 slenderness ratio; the contour shows normal, shear and Von Mises' stress distribution. The straight girder shows a similar distribution of both the normal and Von Mises' stress, and there was very low shear stress. This means that the failure mode was governed by the normal stress caused by major axis bending. On the other hand, these three distributions are quite different for the curved girder. Each flange experienced both compressive and tensile stresses mid-span, and the member is subjected to large amount of shear stress. The Von mises' stress distribution indicates that most of the elements yielded. Therefore, it can be inferred that the dominant factor of failure was the coupling of normal and shear stresses.

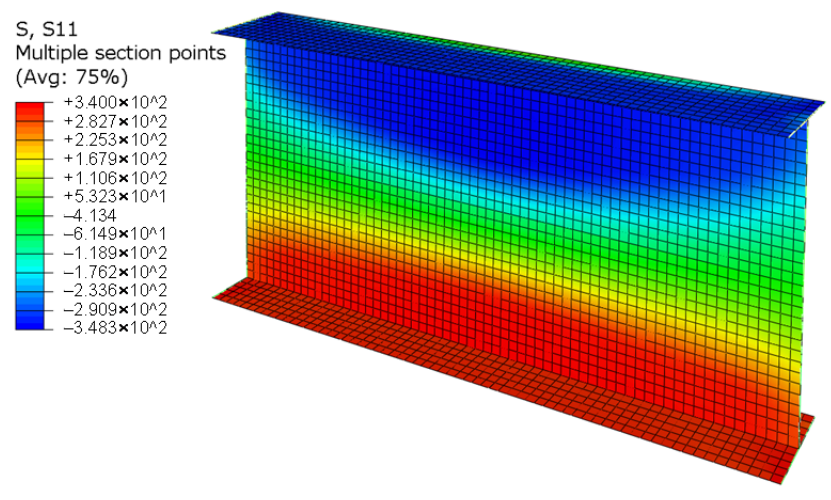

(a)

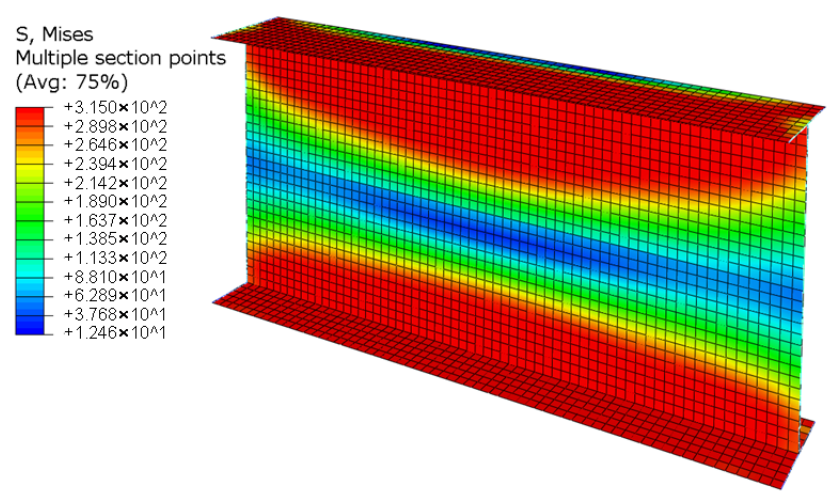

(c)

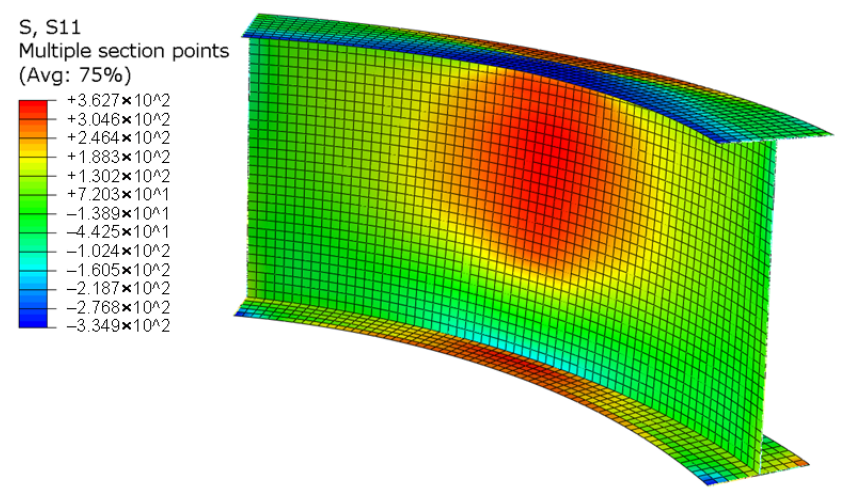

(b)

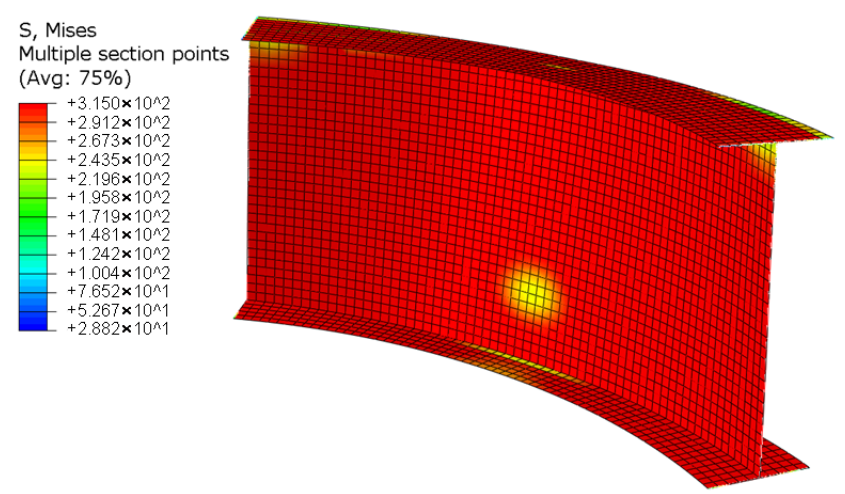

(d)

Figure 7. Cont. 


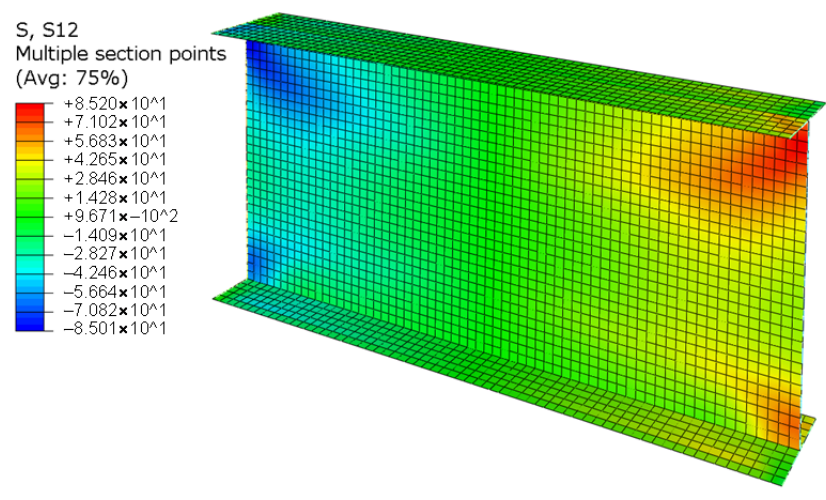

(e)
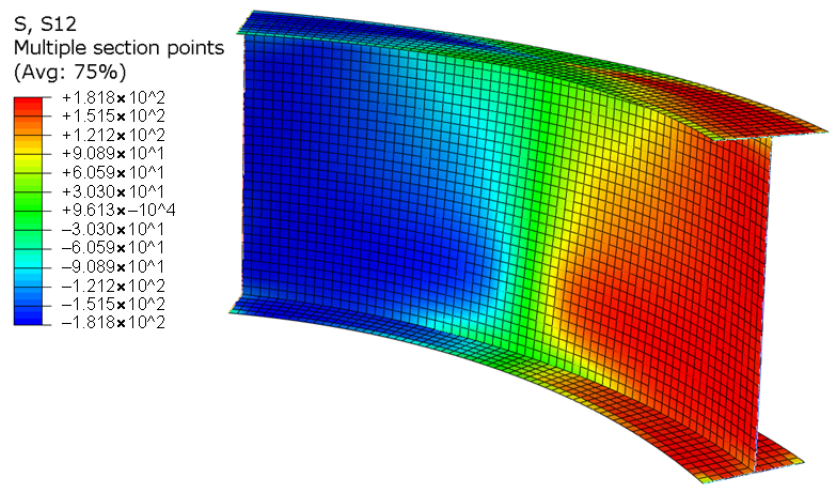

$(\mathbf{f})$

Figure 7. Failure Mode of Straight and Curved Girders; (a) normal stress distribution (Str); (b) normal stress distribution $\left(\theta=60^{\circ}\right)$; (c) Von Mises' stress distribution (Str); (d) Von Mises' stress distribution $\left(\theta=60^{\circ}\right)$. (e) Shear stress distribution (Str); (f) Shear stress distribution $\left(\theta=60^{\circ}\right) .{ }^{*}$ Middle layer.

Lee et al. [23] also discussed the failure mechanism of horizontally curved I-girders, and concluded that there are three main factors that govern the behavior of the curved member: unbraced length, full plastic uniform torsional moment, and curvature effect. However, in their study, the strength equation was only derived for members that have an unbraced length shorter than $1.0 L_{P}$. For short girders, the bending and torsional moment show a linear relationship that can be readily estimated by the function of unbraced length. Since the bending-torsion interaction curves show nonlinear relationships for long (slender) girders, of the three main factors, the slenderness parameter was considered, instead of the unbraced length. By using the slenderness parameter, bending and torsional stiffness were directly considered, so that a more generalized and accurate strength equation could be derived.

Figure 8 representatively describes the bending and torsional moment interaction curves of Sec-A\#1. In the graph, the $X$-axis denotes the normalized (dimensionless) torsional moment ratio, $T_{\max } / T_{P}$, where $T_{\max }$ is the maximum torsional moment calculated by 1st-order analysis when the girder is assumed to be subjected to $M_{P}$ at both ends. The maximum torsional moment would occur at both ends, and could be obtained by Equation (3), derived from the free body diagram.

$$
T(\theta)=\frac{M_{\text {end }} \sin \left(\theta_{\text {end }} / 2-\theta\right)}{\cos \left(\theta_{\text {end }} / 2\right)}
$$

where $M_{\text {end }}=$ applied moment, $\theta_{\text {end }}=$ subtended angle.

$T_{P}$ is the full plastic uniform torque moment obtained by Equation (4) [8]. The torsional moments acting on the open section can be classified into two categories: uniform torsion, and non-uniform (warping) torsion. Therefore, the full plastic torque should be the sum of the full plastic uniform torque and full plastic non-uniform torque. Since it was revealed in a previous study that the uniform torsion affects the ultimate moment strength of the curved member, only the full uniform plastic uniform torque was considered in this study

$$
T_{P}=\frac{f_{y 0}}{\sqrt{3}}\left[b_{f} t_{f}^{2}\left(1-\frac{t_{f}}{3 b_{f}}\right)+\left(h-2 t_{f}\right) \frac{t_{w}^{2}}{2}+\frac{t_{w}^{3}}{6}\right]
$$

where $f_{y 0}=$ uniaxial initial yield stress.

In short, the dimensionless torsional moment ratio has two main factors: $T_{P}$ is the torsional capacity of the section, and $T_{\max }$ represents the curvature effect. Since $\lambda$ represents the slenderness of member, the bending-torsion interaction curves in Figure 8 have dominant factors, which are used later in this study to derive the strength equation. 


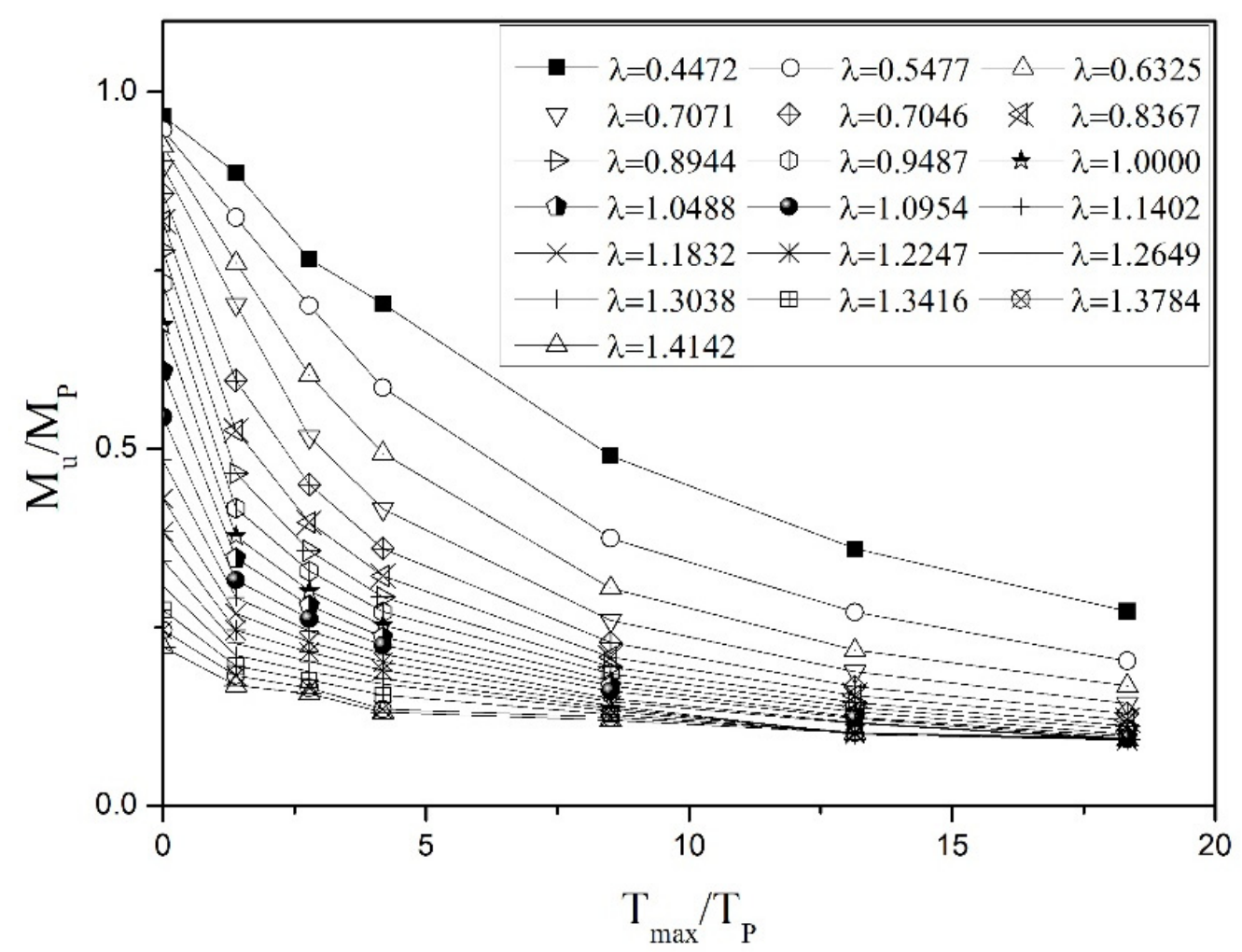

Figure 8. Bending-Torsion Interaction Curves.

To find the general strength equation, regression analyses were carried out. Each interaction curve is convex downward, and could be represented by a simple logarithmic function, as shown in Equation (5), where $A$ and $B$ are constants.

$$
\frac{M_{u}}{M_{P}}=A \ln \frac{T_{\max }}{T_{P}}+B \leq 1.0
$$

In the equation, the preceding clause represents the effect of curvature. In the case of a straight girder, the maximum moment, $T_{\max }$, becomes zero, and the clause will be neglected. The following clause indicates the slenderness effect, which is decided regardless of the subtended angle. Therefore, the strength of any arbitrary member could be estimated by the equation by considering the two different effects individually.

Since three sections were considered, coefficients $A$ and $B$ should be obtained by taking the averages for three members with an identical slenderness ratio. Consequently, $A$ and $B$ could be represented as a function of $\lambda$, as shown in Figures 9 and 10. The coefficient $A$, should be a linear function, while $B$ was expressed by a 3rd degree polynomial, and both can be expressed as Equations (6) and (7).

$$
\begin{gathered}
A=0.26 \lambda-0.38 \\
B=0.36 \lambda^{3}-0.43 \lambda^{2}-1.07 \lambda+1.56
\end{gathered}
$$

Consequently, Equation (5) can be a general equation for any I-shaped section with arbitrary initial curvature and slenderness parameters. Consequently, the derived strength equation contains all the main factors (material, bending and torsional capacity of section, length, slenderness) that affect the ultimate strength of curved members.

\subsection{Verification of the Suggested Equation by FEA}

To verify the accuracy of the suggested equation, additional analyses were carried out. Two of the arbitrary sections were analyzed, and three subtended angles were con- 
sidered for each section. Six slenderness parameters were examined, providing a total of 36 verification models. Table 3 provides the sectional dimension and parameters.

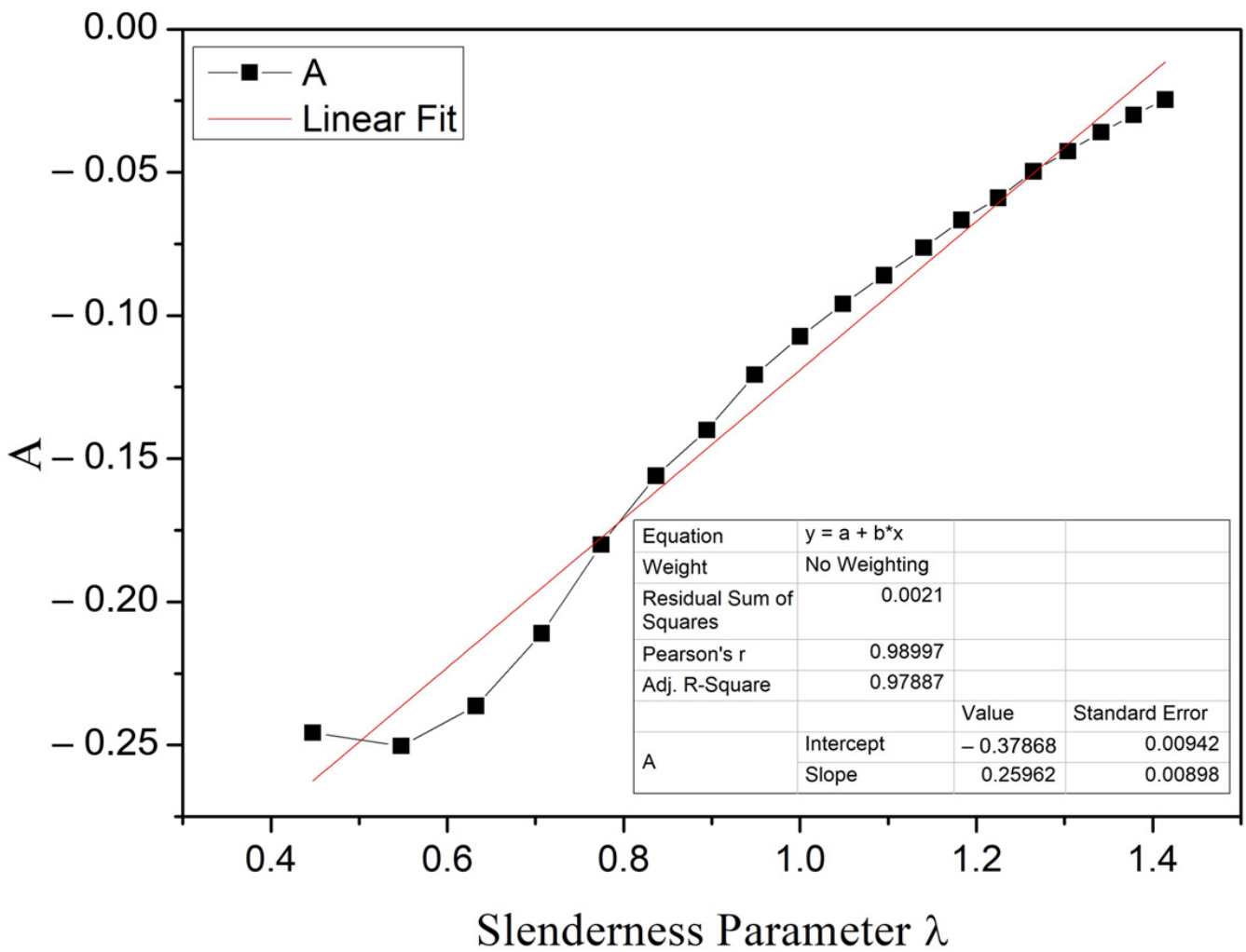

Figure 9. Regression Analysis for Coefficient A.

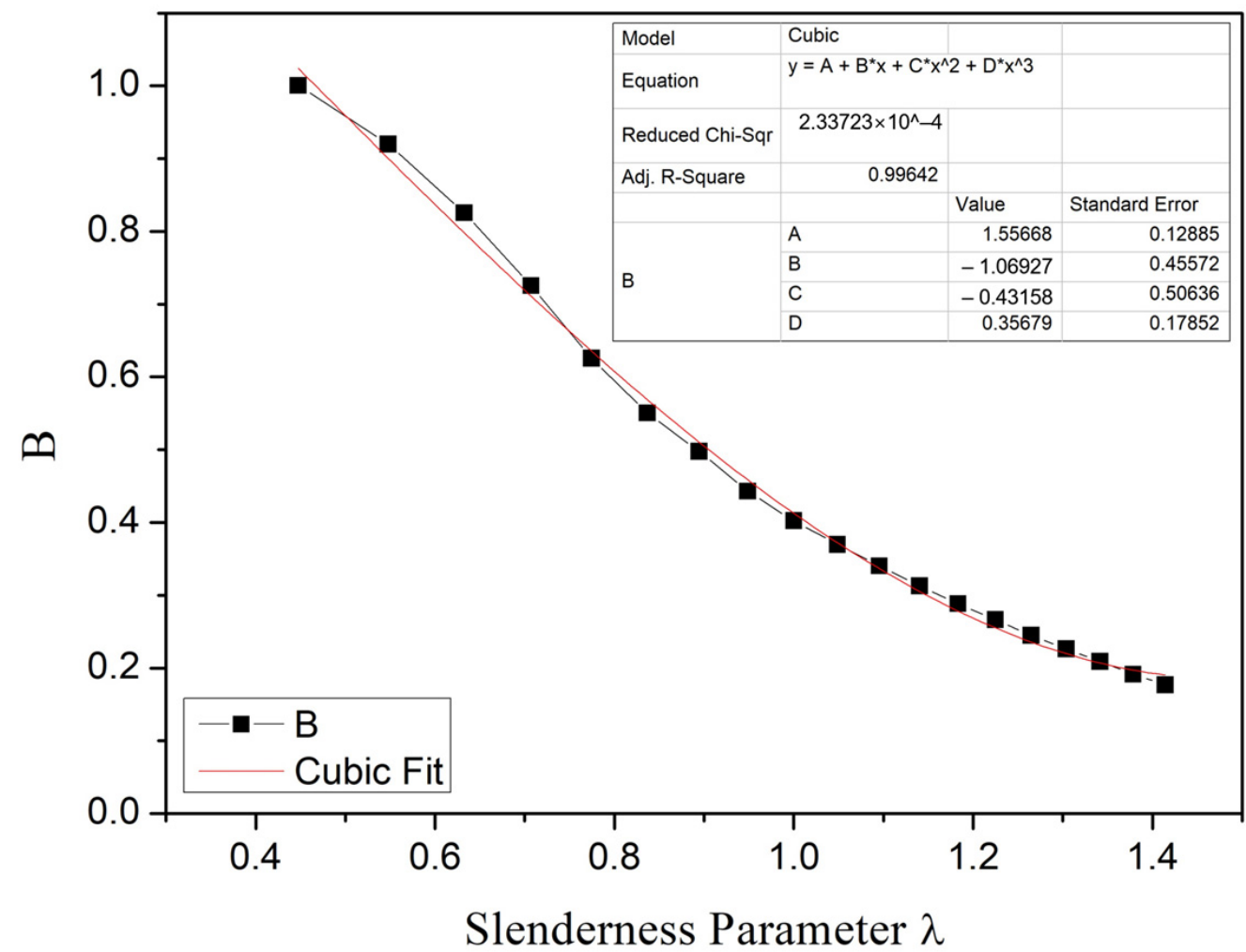

Figure 10. Regression Analysis for Coefficient B. 
Table 3. Dimension of Sections and Parameters.

\begin{tabular}{ccc}
\hline Dimension & Sec-V\#1 & Sec-V\#2 \\
\hline$h(\mathrm{~mm})$ & 400 & 500 \\
$b_{f}(\mathrm{~mm})$ & 100 & 150 \\
$t_{f}(\mathrm{~mm})$ & 20 & 30 \\
$t_{w}(\mathrm{~mm})$ & 15 & 20 \\
$\theta(\mathrm{deg})$ & $15,30,40$ & $13,27,36$ \\
$\lambda$ (Slender ratio) & \multicolumn{2}{c}{$0.2,0.5,0.8,1.0,1.2,1.4$} \\
\hline
\end{tabular}

Figure 11 shows a comparison between the analysis results and the estimated strength by using the suggested equation for all verification analysis models.
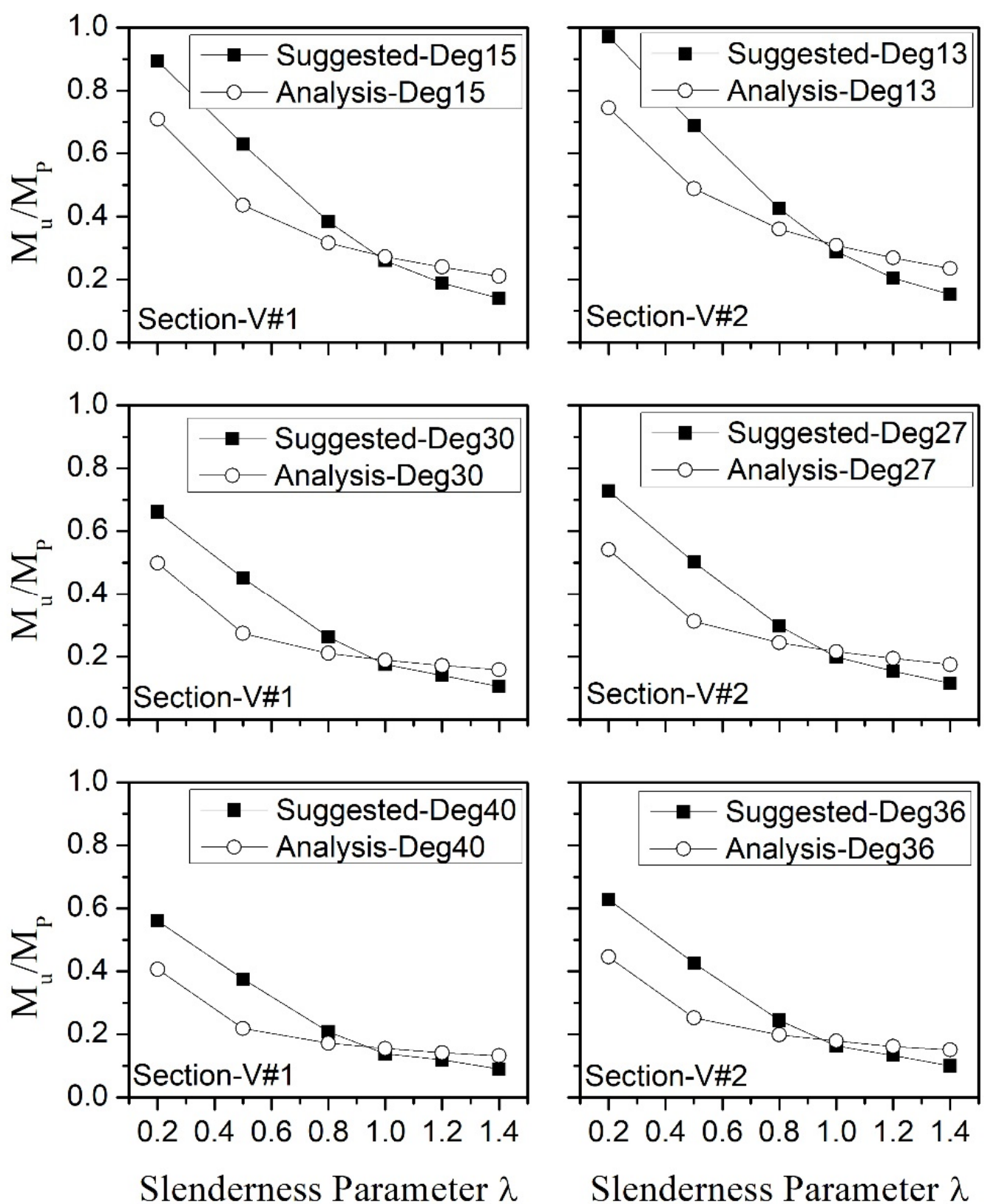

Slenderness Parameter $\lambda$

Figure 11. Verification Analysis.

The equation showed good agreement, with a 5.05\% average difference. However, for the members with a slenderness ratio less than 1 , the equation tends to overestimate the 
ultimate strength by over $10 \%$, while it underestimates ultimate strength by approximately $4 \%$ for slender members.

\section{Experimental Study}

\subsection{Test Setup and Measurements}

The experimental study was carried out to investigate the behavior of a curved member and verify the accuracy of the suggested equation. To realize a member that is subjected to a uniform moment for the entire span, straight overhangs were introduced at both sides, as shown in Figure 12. The loads were applied at both ends of the overhang (side span), so that the end moment could be calculated by multiplying load by arm length. While the mid-span is subjected to pure negative moment, there should be both bending moment and shear force at the overhangs (side span). Therefore, bearing stiffeners were utilized at the side spans to avoid shear failure. To prevent excessive deformation of the overhang, the loading speed was set to $2 \mathrm{~mm} / \mathrm{min}$ (displacement control).
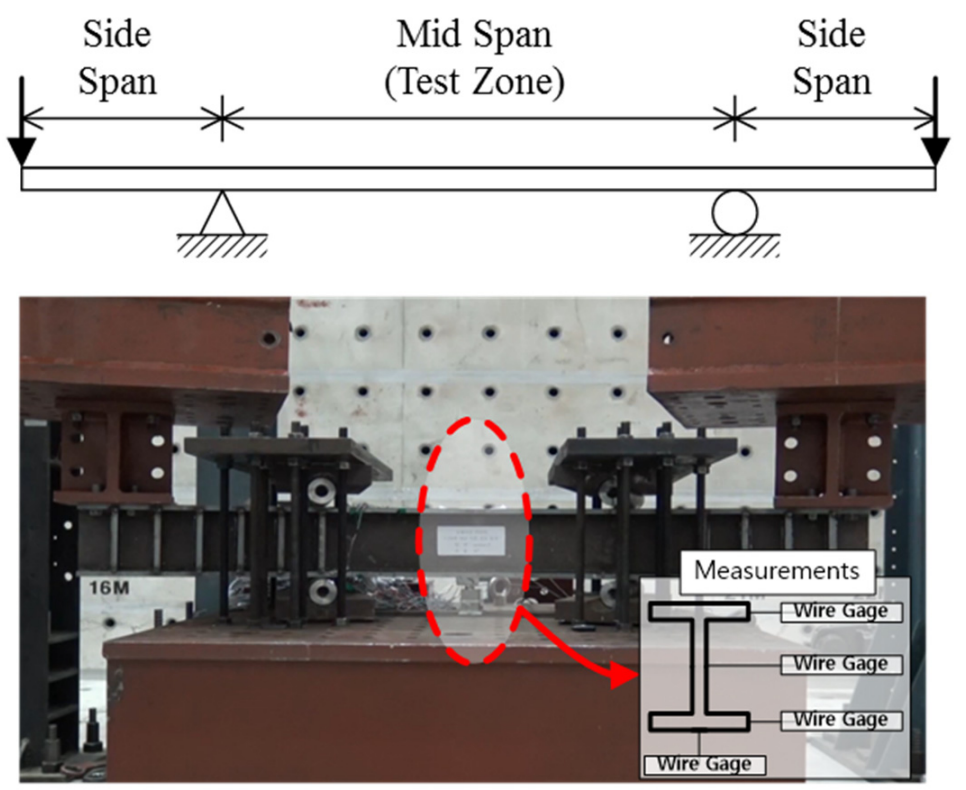

Figure 12. Test Setup/Displacement Measurements.

The simply supported condition was utilized by employing two rollers at each support. To provide rotational restraint at the supports, an additional roller and plate was devised. The use of two rollers prevented rotational and vertical displacement. Figures 13 and 14 show the loading and boundary condition of the test specimen.

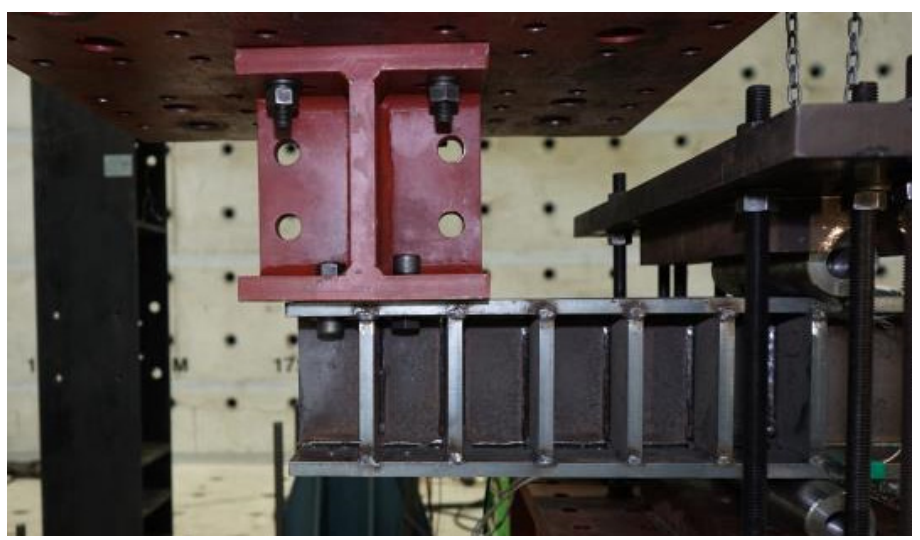

Figure 13. Loading Condition. 


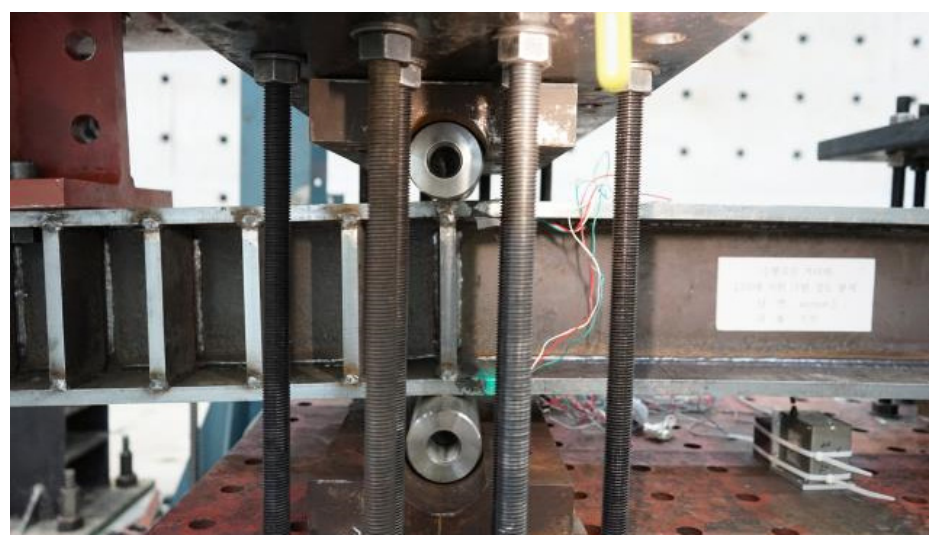

Figure 14. Boundary Condition.

Four wire gages were used to determine the vertical and horizontal displacements at the mid-point of the test zone. The vertical displacement was measured at the compression flange, while the horizontal displacements were measured by three wire gages at the compression and tension flanges, and at the shear center. The rotational angle was calculated from the horizontal displacements.

There were 12 specimens, and the span length of the mid span (test zone) was fixed at $900 \mathrm{~mm}$. Therefore, the slenderness parameters were controlled by the section dimensions. To prevent local buckling behavior, the thickness of flange and web should satisfy the slenderness limit to meet the compact section requirement. Moreover, since there was no transverse and longitudinal stiffener in the test zone, the height of the web was also limited to prevent shear buckling. Shear buckling would not occur in pure-moment conditions, but shear stress could be generated for curved members, because curved geometry causes simultaneous torsional and bending moments.

Specimens were designed to have four subtended angles of $0,5,15$, and $30^{\circ}$. Table 4 lists the sections and parameters. According to AASHTO, the proportional limits of the compression flange and web were checked to prevent local failure, such as flange local buckling or web bend buckling.

Table 4. Dimension of Sections and Parameters.

\begin{tabular}{cccc}
\hline Dimension & Sec-T\#1 & Sec-T\#2 & Sec-T\#3 \\
\hline$h(\mathrm{~mm})$ & 202 & 202 & 204 \\
$b_{f}(\mathrm{~mm})$ & 219.8 & 171.2 & 142.16 \\
$t_{f}(\mathrm{~mm})$ & 18 & 18 & 16 \\
$t_{w}(\mathrm{~mm})$ & 10 & 12 & 12 \\
$\lambda$ (Slender ratio) & 0.189 & 0.246 & 0.301 \\
$\theta$ (deg) & & $0,5,15,30$ & \\
\hline
\end{tabular}

\subsection{Material Test}

For the specimen, SM490 steel was used, which is provided in the LRFD Highway Design Specifications [28]. The material was supposed to have $315 \mathrm{MPa}$ minimum yield stress, and $490 \mathrm{MPa}$ ultimate stress. In order to verify and identify the material properties, coupon tests were carried out before the experiment. Since the flanges and web of each specimen had different thicknesses and were manufactured separately, the coupon tests were performed individually, according to their thickness. Three coupons were made for each thickness, and the average value was used for the result analyses. Figure 15 shows the material test and specimens, while Table 5 lists the results. The average yield stress was $350.35 \mathrm{MPa}$, which was used in finite-element analysis. 


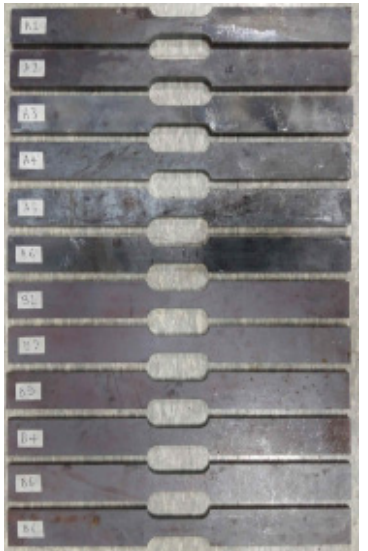

(a)

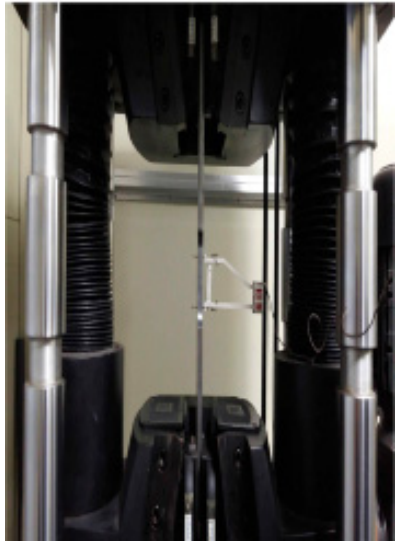

(b)

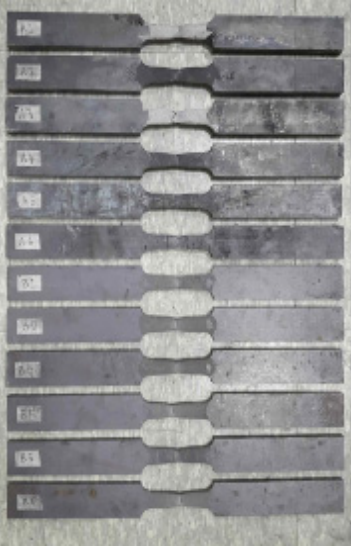

(c)

Figure 15. Coupon Test; (a) specimens before test; (b) test setup; (c) specimens after test.

Table 5. Material Properties.

\begin{tabular}{|c|c|c|c|c|c|c|}
\hline $\begin{array}{c}\text { Thickness } \\
\text { (mm) }\end{array}$ & $\begin{array}{c}\text { Elastic } \\
\text { Modulus } \\
(\mathrm{GPa})\end{array}$ & $\begin{array}{c}\text { Average } \\
\text { Elastic } \\
\text { Modulus } \\
\text { (GPa) }\end{array}$ & $\begin{array}{l}\text { Yield } \\
\text { Stress } \\
\text { (MPa) }\end{array}$ & $\begin{array}{c}\text { Average } \\
\text { Yield } \\
\text { Stress } \\
(\mathrm{MPa})\end{array}$ & $\begin{array}{l}\text { Ultimate } \\
\text { Stress } \\
\text { (MPa) }\end{array}$ & $\begin{array}{c}\text { Average } \\
\text { Ultimate } \\
\text { Stress } \\
\text { (MPa) }\end{array}$ \\
\hline 17.9 & 206.1 & \multirow{3}{*}{205.9} & 344.6 & \multirow{3}{*}{341.8} & 549.5 & \multirow{3}{*}{550.5} \\
\hline 17.9 & 205.8 & & 339.4 & & 552.9 & \\
\hline 18 & 205.9 & & 341.5 & & 549.2 & \\
\hline 16.1 & 205.7 & \multirow{3}{*}{206.0} & 345.8 & \multirow{3}{*}{344.1} & 557.2 & \multirow{3}{*}{554} \\
\hline 16.3 & 206.1 & & 341.8 & & 546.8 & \\
\hline 15.9 & 206.1 & & 344.8 & & 558 & \\
\hline 11.8 & 206.2 & \multirow{3}{*}{206.0} & 343.7 & \multirow{3}{*}{345.2} & 531 & \multirow{3}{*}{530.2} \\
\hline 11.8 & 206.1 & & 346.6 & & 530.6 & \\
\hline 11.7 & 205.8 & & 345.2 & & 528.9 & \\
\hline 9.8 & 206.2 & \multirow{3}{*}{206.1} & 370.8 & \multirow{3}{*}{370.3} & 531.2 & \multirow{3}{*}{527.3} \\
\hline 9.9 & 206.1 & & 372.3 & & 522.2 & \\
\hline 9.8 & 205.9 & & 367.7 & & 528.4 & \\
\hline Average & \multicolumn{2}{|c|}{206.0} & \multicolumn{2}{|c|}{350.35} & \multicolumn{2}{|c|}{540.5} \\
\hline
\end{tabular}

\subsection{Test Results}

Figure 16 shows the load-displacement curves of the test specimens. Horizontal, vertical, and rotational displacements are illustrated with normalized moments. Firstly, the horizontal and rotational displacements of straight members were very small, while the vertical displacement was relatively large. The straight members resisted the plastic moment, and no buckling behavior was observed.

Meanwhile, the ultimate moment decreased with the increase in subtended angle. Most of the curved beams showed failure before the loads reached the plastic moment, and the failure modes could be explained by examination of the displacement patterns. The horizontal displacement of curved members was mostly greater than the vertical displacement, and the rotational angle was also much greater than that of straight girders. Since there were no local or unexpected specimen failures, it can be inferred that the decreases in ultimate strength were caused by bending-torsion interaction (note that a specimen with Sec-T\#3 that has $15^{\circ}$ of subtended angle showed a failure at overhang, so the specimen was excluded from the results analysis).

Figure 17 shows a comparison between the suggested equation and the test results, according to the subtended angle. The two curves show very good agreement, with an average difference $\left(M_{\text {suggested }}-M_{\text {test }}\right)$ of $0.03 M_{P}$. Notably, for the members with a 
subtended angle of $(15 \text { and } 30)^{\circ}$, the equation could almost evaluate the exact ultimate strength. This means the strength decrease rate due to the subtended angle could be traced by the equation.

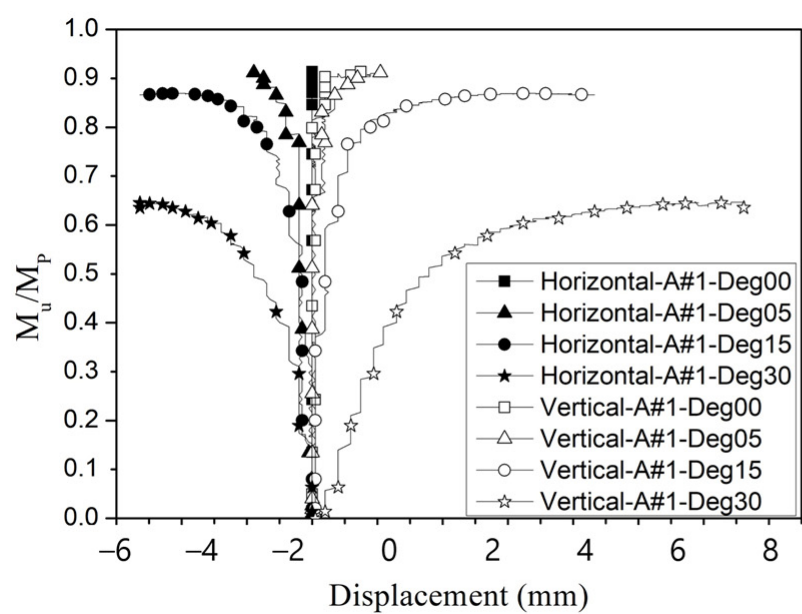

(a)
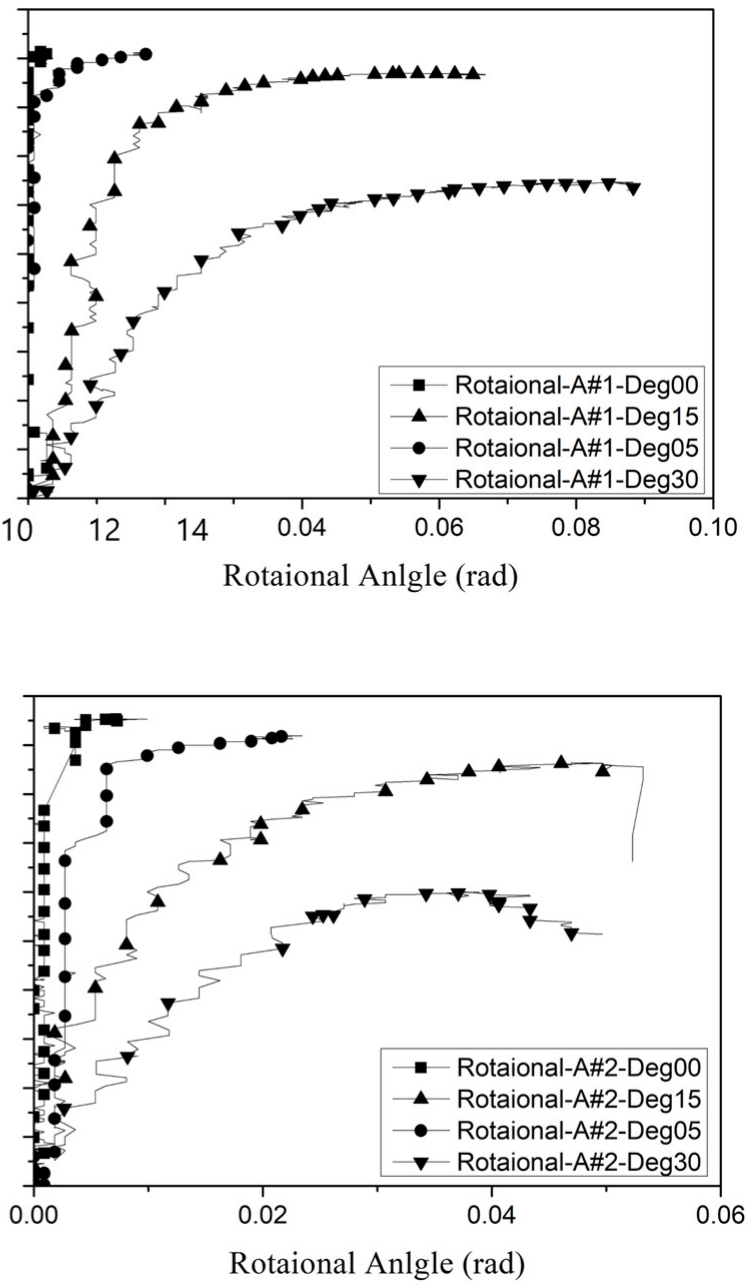

(b)

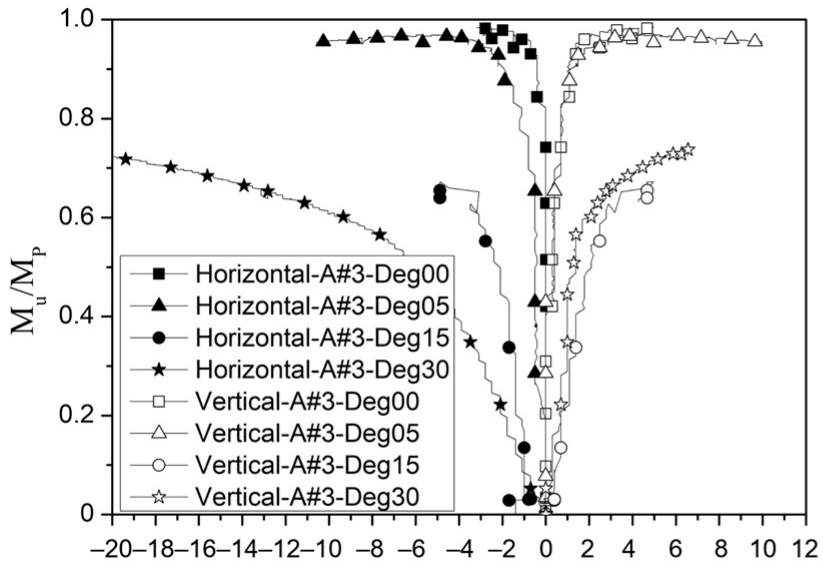

Displacement (mm)

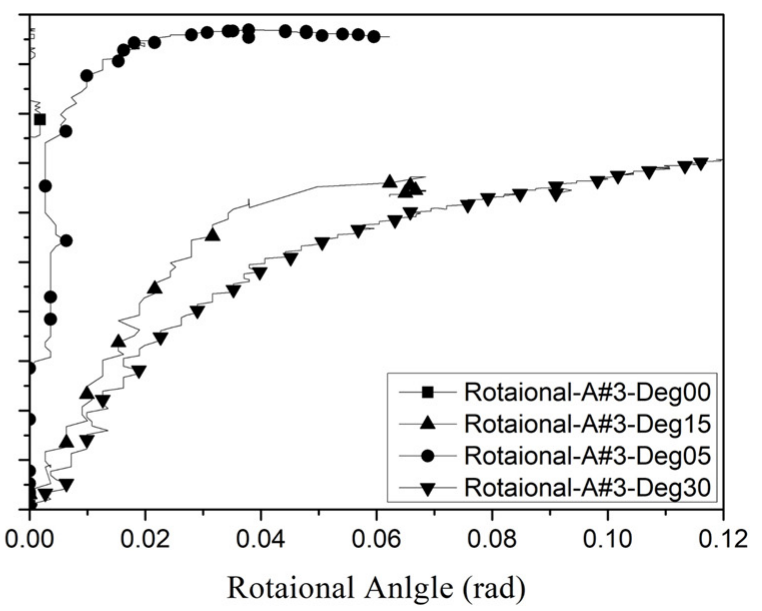

(c)

Figure 16. Load-Displacement Curves; (a) test specimen Sec-T\#1; (b) test specimen Sec-T\#2; (c) test specimen Sec-T\#3. 

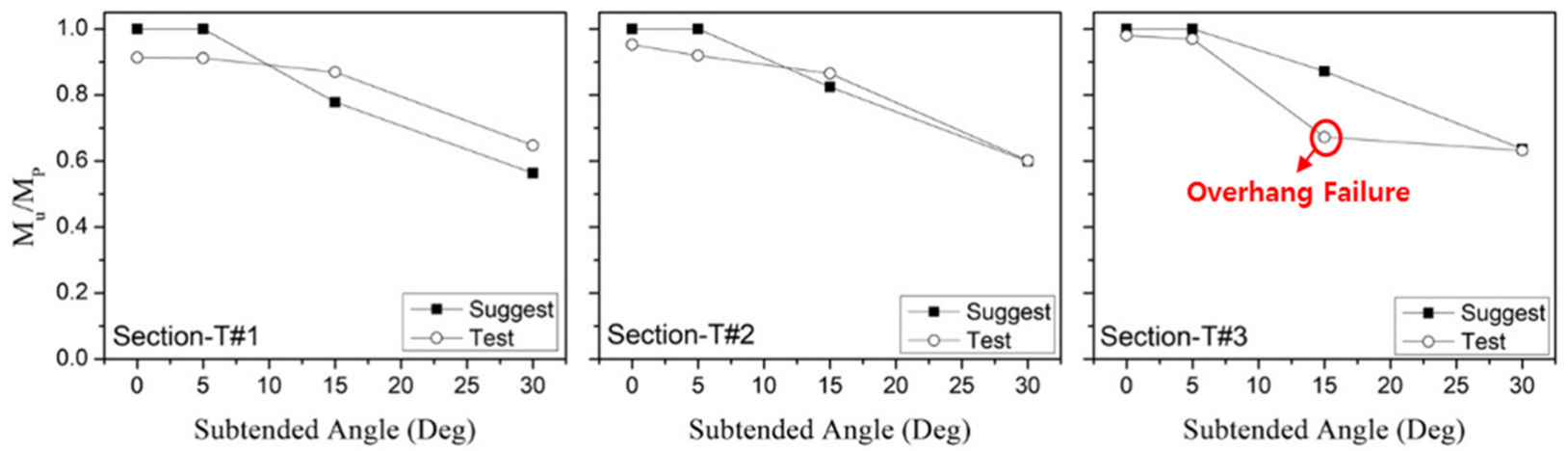

Figure 17. Ultimate Strength Comparison per Subtended Angle.

On the other hand, Figure 18 shows the results per slenderness parameter. According to the suggested equation, six specimens out of 12 should resist the plastic moment. However, a member in a real structure is rarely subjected to plastic moment for several reasons, such as initial imperfections and material irregularities. Consequently, the average accuracy of the equation was $94.1 \%$, with overestimated strength. In contrast, for relatively sharply curved members, the accuracy was $99.7 \%$, which led to conservative results (underestimated strength).
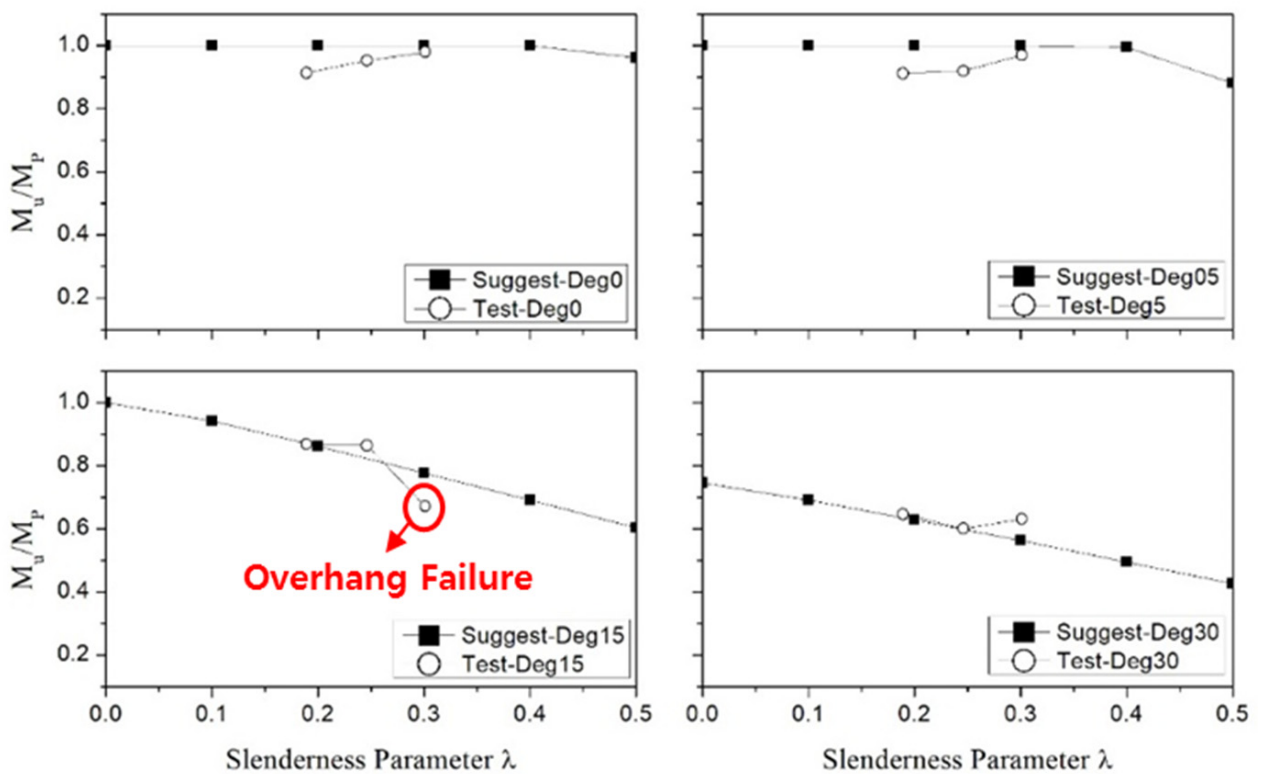

Figure 18. Ultimate Strength Comparison per Slenderness Parameter.

\section{Conclusions}

Since a horizontally curved girder is always subjected to torsional moment, the strength should be governed by both bending and torsional moment. As a result of this research, a unified strength equation for curved and straight members has been provided. The equation included all the factors that affect the ultimate behavior. Notably, the slenderness parameter includes not only the length, but also bending and torsional rigidities. Consequently, the equation could accurately trace the ultimate strength for curved members showing highly nonlinear behavior.

In order to verify the accuracy of the suggested equation, additional analyses and tests were performed. Twelve members were fabricated, of three sections and four subtended angles. Consequently, it was demonstrated that the equation provides very good results for arbitrary sections and subtended angles. Compared with the test results, the accuracy of the equation was nearly $97 \%$. 
The bending-torsional interaction curve is an effective tool for directly dealing with the coupling effect. However, it is hard to calculate the exact torsional moments at the design stage, since curved members show highly nonlinear behavior. In this research, a moment strength equation was derived with the torsional moment obtained from 1st-order analysis. The maximum torsional moment acting on the girder could be normalized by division of the full plastic uniform torque, and indicates the curvature effect. In the case of the straight girder, the torsional moment should be zero, so that the curvature effect can be neglected.

The straight member should be regarded as a kind of curved member that has 0 degree of subtended angle. The suggested equation not only reflects this concept, but also has a simple form. It is expected that the results of this study could provide easy and useful information for the design of curved members.

Author Contributions: Conceptualization, Y.-J.K.; methodology, J.L. (Jeonghyeon Lim) and K.L.; software, J.L. (Jeonghyeon Lim); validation, J.L. (Jeonghyeon Lim); formal analysis, J.L. (Jeonghyeon Lim) and K.L.; investigation, J.L. (Jeonghyeon Lim) and K.L.; resources, J.L. (Jeonghwa Lee); data curation, J.L. (Jeonghyeon Lim) and K.L.; writing-original draft preparation, J.L. (Jeonghyeon Lim) and K.L.; writing—review and editing, Y.-J.K. and S.K.; visualization, J.L. (Jeonghyeon Lim); supervision, Y.-J.K.; project administration, S.K.; funding acquisition, K.L. All authors have read and agreed to the published version of the manuscript.

Funding: This research was funded by Seoul Institute of Technology (SIT), (2020-AA-001).

Institutional Review Board Statement: Not applicable.

Informed Consent Statement: Not applicable.

Data Availability Statement: Data are contained within the article.

Acknowledgments: This work was supported by Seoul Institute of Technology (SIT) (2020-AA-001, Deformed shape estimation of bridges based on measured data).

Conflicts of Interest: The authors declare no conflict of interest.

\section{References}

1. Fukumoto, Y.; Nishida, S. Ultimate Load Behavior of Curved I-Beams. J. Eng. Mech. Div. 1981, 107, 367-385. [CrossRef]

2. Yoshida, H.; Maegawa, K. Ultimate Strength Analysis of Curved I-Beams. J. Eng. Mech. 1983, 109, 192-214. [CrossRef]

3. Fujii, F.; Gong, S. Field Transfer Matrix for Nonlinear Curved Beams. J. Struct. Eng. 1988, 114, 675-692. [CrossRef]

4. Liew, J.R.; Thevendran, V.; Shanmugam, N.; Tan, L. Behaviour and design of horizontally curved steel beams. J. Constr. Steel Res. 1995, 32, 37-67. [CrossRef]

5. Kang, Y.J.; Yoo, C.H. Thin-Walled Curved Beams. I: Formulation of Nonlinear Equations. J. Eng. Mech. 1994, $120,2072-2101$. [CrossRef]

6. Thin-Walled Curved Beams. II: Analytical Solutions for Buckling of Arches. J. Eng. Mech. 1994, 120. [CrossRef]

7. Pi, Y.-L.; Trahair, N.S. Nonlinear Elastic Behavior of I-Beams Curved in Plan. J. Struct. Eng. 1997, 123, 1201-1209. [CrossRef]

8. Pi, Y.-L.; Bradford, M.; Trahair, N.S. Inelastic Analysis and Behavior of Steel I-Beams Curved in Plan. J. Struct. Eng. 2000, 126, 772-779. [CrossRef]

9. Pi, Y.-L.; Bradford, M. Strength Design of Steel I-Section Beams Curved in Plan. J. Struct. Eng. 2001, 127, 639-646. [CrossRef]

10. Yoo, C.H.; Davidson, J.S. Yield Interaction Equations for Nominal Bending Strength of Curved I-Girders. J. Bridg. Eng. 1997, 2, 37-44. [CrossRef]

11. Davidson, J.S.; Yoo, C.H. Evaluation of Strength Formulations for Horizontally Curved Flexural Members. J. Bridg. Eng. 2000, 5, 200-207. [CrossRef]

12. Fasl, J.D.; Stith, J.C.; Helwig, T.A.; Schuh, A.; Farris, J.; Engelhardt, M.D.; Williamson, E.B.; Frank, K.H. Instrumentation of a Horizontally Curved Steel I-Girder Bridge during Construction. J. Struct. Eng. 2015, 141. [CrossRef]

13. Amani, M.; Alinia, M. The flexural behavior of horizontally curved steel I-girder bridge systems and single-girders. J. Constr. Steel Res. 2016, 118, 145-155. [CrossRef]

14. Issa-El-Khoury, G.; Linzell, D.G.; Geschwindner, L.F. Flexure-shear interaction influence on curved, plate girder web longitudinal stiffener placement. J. Constr. Steel Res. 2016, 120, 25-32. [CrossRef]

15. Tsiptsis, I.N.; Sapountzakis, E.J. Generalized warping and distortional analysis of curved beams with isogeometric methods. Comput. Struct. 2017, 191, 33-50. [CrossRef]

16. McElwain, B.A.; Laman, J.A. Experimental Verification of Horizontally Curved I-Girder Bridge Behavior. J. Bridg. Eng. 2000, 5, 284-292. [CrossRef] 
17. Shanmugam, N.; Mahendrakumar, M.; Thevendran, V. Ultimate load behaviour of horizontally curved plate girders. J. Constr. Steel Res. 2003, 59, 509-529. [CrossRef]

18. Linzell, D.; Leon, R.T.; Zureick, A.H. Experimental and Analytical Studies of a Horizontally Curved Steel I-Girder Bridge during Erection. J. Bridg. Eng. 2004, 9, 521-530. [CrossRef]

19. Thevendran, V.; Chen, S.; Shanmugam, N.; Liew, R. Nonlinear analysis of steel-concrete composite beams curved in plan. Finite Elements Anal. Des. 1999, 32, 125-139. [CrossRef]

20. Thevendran, V.; Shanmugam, N.; Chen, S.; Liew, J. Experimental study on steel-concrete composite beams curved in plan. Eng. Struct. 2000, 22, 877-889. [CrossRef]

21. Tan, E.; Uy, B. Experimental study on straight composite beams subjected to combined flexure and torsion. J. Constr. Steel Res. 2009, 65, 784-793. [CrossRef]

22. Tan, E.; Uy, B. Experimental study on curved composite beams subjected to combined flexure and torsion. J. Constr. Steel Res. 2009, 65, 1855-1863. [CrossRef]

23. Lee, K.; Davidson, J.S.; Choi, J.; Kang, Y. Ultimate strength of horizontally curved steel I-girders with equal end moments. Eng. Struct. 2017, 153, 17-31. [CrossRef]

24. Galambos, T.V.; Ketter, R.L. Columns under Combined Bending and Thrust. Trans. Am. Soc. Civ. Eng. 1961, 126, 1-23. [CrossRef]

25. Steel Construction Manual, 15th Ed. (Print) American Institute of Steel Construction. Available online: https://www.aisc.org/ Steel-Construction-Manual-15th-Ed-Print (accessed on 25 June 2021).

26. NCCI: Elastic Critical Moment for Lateral Torsional Buckling—PDF Free Download. Available online: https://docplayer.net/48 950705-Ncci-elastic-critical-moment-for-lateral-torsional-buckling.html (accessed on 25 June 2021).

27. AASHTO. Aashto Lrfd Bridge. Design Specifications, 8th ed.; American Association of State Highway and Transportation Officials: Washington, DC, USA, 2020.

28. Ministry of Land, Transport and Maritime Affairs. LRFD Highway Bridge. Design Specifications; Ministry of Land, Transport and Maritime Affairs: Sejong, Korea, 2012. 